\title{
Review
}

\section{Physical capacity in wheelchair-dependent persons with a spinal cord injury: a critical review of the literature}

\author{
JA Haisma*,1, LHV van der Woude ${ }^{2,3}$, HJ Stam ${ }^{1}$, MP Bergen ${ }^{4}$, TAR Sluis ${ }^{4}$ and JBJ Bussmann ${ }^{1}$ \\ ${ }^{1}$ Department of Rehabilitation Medicine, Erasmus MC, University Medical Centre, Rotterdam, The Netherlands; \\ ${ }^{2}$ Faculty of Human Movement Sciences, Institute for Fundamental and Clinical Human Movement Sciences, \\ Vrije Universiteit Amsterdam, Amsterdam, The Netherlands, ${ }^{3}$ Rehabilitation Centre Amsterdam, Amsterdam, \\ The Netherlands; ${ }^{4}$ Rijndam Rehabilitation Centre, Rotterdam, The Netherlands
}

\begin{abstract}
Study design: Review of publications.
Objective: To assess the level of physical capacity (peak oxygen uptake, peak power output, muscle strength of the upper extremity and respiratory function) in wheelchair-dependent persons with a spinal cord injury (SCI).

Setting: Erasmus MC, University Medical Centre Rotterdam, The Netherlands.

Methods: Pubmed (Medline) search of publications from 1980 onwards. Studies were systematically assessed. Weighted means were calculated for baseline values.

Results: In tetraplegia, the weighted mean for peak oxygen uptake was $0.891 / \mathrm{min}$ for the wheelchair exercise test (WCE) and $0.871 / \mathrm{min}$ for arm-cranking or hand-cycling (ACE). The peak power output was $26 \mathrm{~W}$ (WCE) and $40 \mathrm{~W}$ (ACE). In paraplegia, the peak oxygen uptake was $2.101 / \mathrm{min}$ (WCE) and $1.51 \mathrm{l} / \mathrm{min}$ (ACE), whereas the peak power output was $74 \mathrm{~W}$ (ACE) and $85 \mathrm{~W}$ (WCE). In paraplegia, muscle strength of the upper extremity and respiratory function were comparable to that in the able-bodied population. In tetraplegia muscle strength varied greatly, and respiratory function was reduced to $55-59 \%$ of the predicted values for an age-, gender- and height-matched able-bodied population.

Conclusions: Physical capacity is reduced and varies in SCI. The variation between results is caused by population and methodological differences. Standardized measurement of physical capacity is needed to further develop comparative values for clinical practice and rehabilitation research.

Sponsorship: Supported by the Health Research and Development Council of The Netherlands (grant nos. 1435.0003; 1435.0025).

Spinal Cord (2006) 44, 642-652. doi:10.1038/sj.sc.3101915; published online 14 March 2006
\end{abstract}

Keywords: review; spinal cord injury; physical endurance; exercise tolerance; muscle weakness; respiratory function

\section{Introduction}

Physical capacity can be described as the capacity of the cardiovascular system, muscle groups and the respiratory system to provide a level of physical activity. ${ }^{1}$ It is reduced in persons with a spinal cord injury (SCI) by the direct loss of motor control and sympathetic influence below the level of lesion. Additionally, the majority of persons with an SCI will be wheelchair users and dependent on arm work for mobility and activities of daily living. Subsequently, an inactive lifestyle may further reduce physical capacity. ${ }^{2,3}$

\footnotetext{
*Correspondence: JA Haisma, Department of Rehabilitation Medicine, Erasmus MC, University Medical Centre, PO Box 2040, 3000 CA Rotterdam, The Netherlands
}

A low level of physical capacity is associated with a decrease in activity, ${ }^{3,4}$ functional status ${ }^{5,6}$ and participation. ${ }^{2,7}$ This may result in the vicious circle of decreased physical capacity leading to decreased activity and participation, which further reduces physical capacity, and so on. Furthermore, a low level of physical capacity is associated with a high risk of medical (cardiovascular) complications. ${ }^{8,9}$ The association of a low level of physical capacity with a relapse in different aspects of health may contribute to a reduction in quality of life. ${ }^{6,10,11}$ Hence, the evaluation of physical capacity can give an indication of the potential level of activity, participation and quality of life., ${ }^{2,6,7}$

Clinicians and rehabilitation researchers need comparative values for different components of physical 
capacity (ie peak oxygen uptake, peak power output, muscle strength of the upper extremity and respiratory function). ${ }^{3}$ This will help them to set targets in SCI rehabilitation. ${ }^{12}$ Additionally, monitoring changes in physical capacity may give an indication of the effectiveness of training and rehabilitation programmes. ${ }^{13}$ Persons with an SCI may become motivated to participate in exercise programmes when they learn about their health status and how it evolves.

Although much research has focused on physical capacity in SCI, the reported level of physical capacity varies greatly. This could be attributed to the disparity in population, methodology and presentation of results, which hamper comparisons and generalization. $1,3,10$ Furthermore, few studies have addressed more than one component of physical capacity simultaneously. $1,3,12$

Therefore, the purpose of this study was to integrate evidence on different components of physical capacity in SCI, by critically analysing absolute values and (in)consistencies in the literature. This way a set of comparative values for components of physical capacity in this population may be obtained. We formulated the following research question: What is the reported level of peak oxygen uptake, peak power output, muscle strength of the upper extremity and respiratory function in persons with an SCI who are wheelchair-dependent?

\section{Methods}

Data search

To gain insight into the level of physical capacity in SCI, we searched Pubmed (Medline) and included publications from 1980 onwards. SCI-related studies were explored with the Medical Subject Headings (MeSH) 'spinal cord disease' and the terms tetraplegia, quadriplegia or paraplegia. This search was combined with the following MeSH headings: 'physical fitness', 'oxygen consumption', 'exercise test' or 'spirometry'. Then the search was combined with one of the following terms: wheelchair ergometry, endurance, physical capacity, manual muscle testing, handheld dynamometry or myometry. Additionally, we scanned the references in studies, and experts checked the resultant list of studies for completeness.

\section{Selection on topic-related criteria}

To be eligible for inclusion, a study had to specify the following items: (1) Results for subjects with an SCI who were wheelchair-dependent. (2) Whether results concerned subjects with a tetraplegia or a paraplegia. (3) One of the following outcome parameters: (i) peak oxygen uptake $\left(V \mathrm{O}_{2 \text { peak }} ; 1 / \mathrm{min}\right.$ or $\left.\mathrm{ml} / \mathrm{min}\right)$ and $/$ or peak power output $\left(\mathrm{PO}_{\text {peak }} ; \mathrm{W}\right.$ or $\left.\mathrm{kpm} / \mathrm{min}\right)$ measured by a wheelchair exercise test (WCE), arm-cranking or handcycling (ACE); (ii) manual muscle testing (MMT) grade or handheld dynamometry score (HHD; Newton or $\mathrm{kg}$ ) for the upper extremity; (iii) forced expiratory flow per second (FEV1) or forced vital capacity (FVC) as absolute values in litres, or as a percentage of the predicted values for an age-, gender- and heightmatched able-bodied population; (4) The method used. Figure 1 shows a flowchart for the study search and selection.

\section{Selection on methodological criteria}

The resultant 67 studies were assessed on their methodological quality. Because we were interested in baseline values of physical capacity, we abbreviated an established checklist for the evaluation of effect studies. ${ }^{14,15}$ Studies that specified seven of the following items were assumed to be methodologically fit for inclusion. (1) Inclusion and exclusion criteria. (2) Source of selected population. (3) Description of subjects. (4) Inclusion of $\geqslant 10$ subjects with a tetraplegia or $\geqslant 10$ subjects with a paraplegia. (5) Outcome measure. (6) Details on the measuring protocol. (7) Statistical method. (8) Means and standard deviations. (9) Number of dropouts. (10) Reasons for not completing tests. Two studies were excluded, because they fulfilled only six of these criteria. A total of 13 studies were excluded, because they concerned doubly reported data.

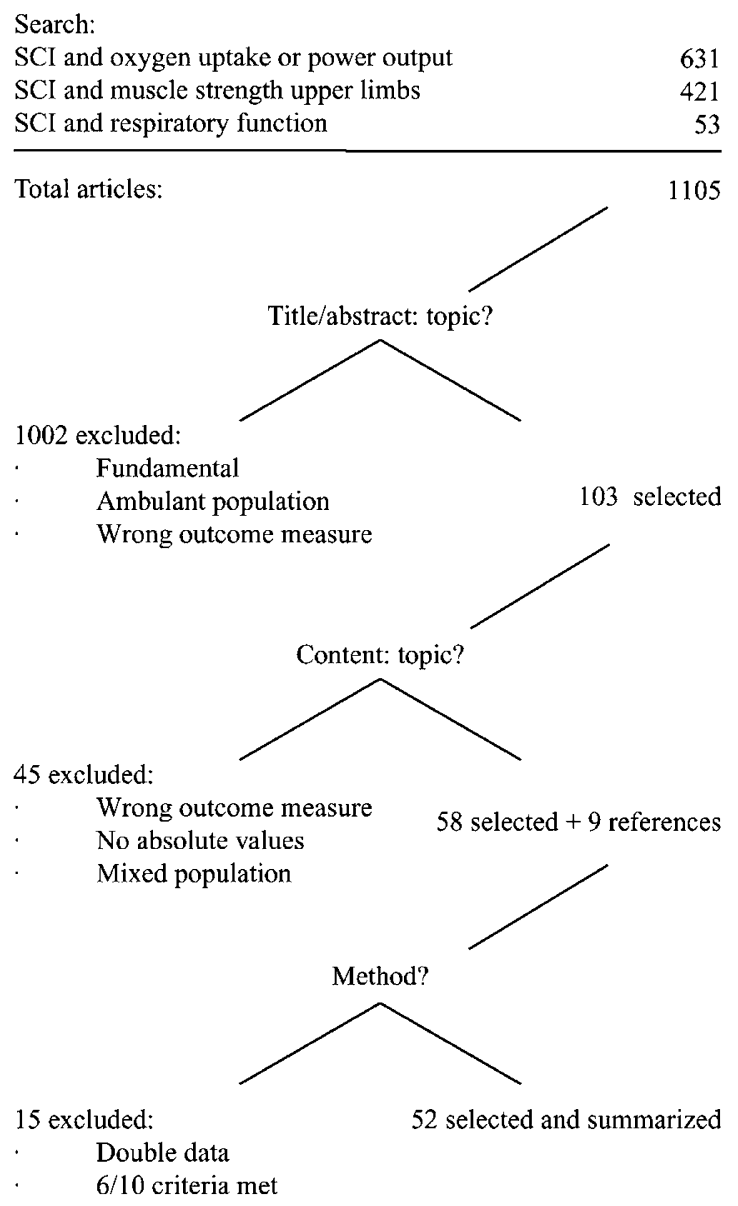

Figure 1 Flowchart for search and selection of studies on physical capacity 


\section{Data extraction}

A data extraction form was used to collect information on population characteristics, methods and results. We calculated the weighted means of the combined results.

\section{Results}

Tables 1-3 summarize the data of the selected studies. Figures 2 and 3 show mean results for the studies and their combined weighted means.

\section{Peak oxygen uptake and peak power output}

Most selected studies assessed subjects with a paraplegia. Most subjects were men, who participated in sports, were on average 30 years old, and were assessed $>6$ years post-injury. There was variability among the profile used, the starting power output or velocity and the subsequent increments. For paraplegia, the mean $V \mathrm{O}_{2 \text { peak }}$ during the WCE (Table 1a) ranged from 1.10 to $2.511 / \mathrm{min}$ (weighted mean 2.101/min; Figure 2a) and the mean $\mathrm{PO}_{\text {peak }}$ ranged from 46 to $102 \mathrm{~W}$ (weighted mean $74 \mathrm{~W}$; Figure 2b). During ACE (Table 1b), the mean $V \mathrm{O}_{2 \text { peak }}$ ranged from 1.03 to $2.341 / \mathrm{min}$ (weighted mean $1.511 / \mathrm{min}$; Figure $2 \mathrm{a}$ ) and the mean $\mathrm{PO}_{\text {peak }}$ ranged from 66 to $117 \mathrm{~W}$ (weighted mean $85 \mathrm{~W}$; Figure 2b). In subjects with a tetraplegia, the mean $V \mathrm{O}_{2 \text { peak }}$ during WCE (Table 1c) ranged from 0.76 to $1.031 / \mathrm{min}$ (weighted mean $0.891 / \mathrm{min}$; Figure 2a) and the mean $\mathrm{PO}_{\text {peak }}$ ranged from 21 to $33 \mathrm{~W}$ (weighted mean $26 \mathrm{~W}$; Figure 2b). During ACE (Table 1d), the mean $V \mathrm{O}_{2 \text { peak }}$ ranged from 0.78 to $0.951 / \mathrm{min}$ (weighted mean $0.87 \mathrm{l}$ / min; Figure 2a) and the $\mathrm{PO}_{\text {peak }}$ ranged from 35 to $43 \mathrm{~W}$ (weighted mean $40 \mathrm{~W}$; Figure 2b).

\section{Muscle strength of the upper extremity}

Most selected studies assessed subjects with a tetraplegia. Most subjects were men, who were on average 30 years old. Time since injury ranged from 1 month to 6 years. In paraplegia, the mean strength of the shoulder internal rotators was $30.6 \mathrm{~kg}$ and of the external rotators $22.0 \mathrm{~kg} .{ }^{44}$ For subjects with tetraplegia, these values were 14.8 and $11.7 \mathrm{~kg}$, respectively. ${ }^{44}$ The elbow flexion in subjects with tetraplegia ranged from 4.0 to $9.2 \mathrm{~kg} .47,49,52$ The mean strength for wrist extension was $6.5 \mathrm{~kg} .{ }^{47}$ Elbow extension scored between 8.0 and $11.1 \mathrm{~kg} .{ }^{47}$

MMT grades were used varyingly. One study reported a mean shoulder flexion of grade 3.7 and a mean shoulder extension of $3.6 .^{45}$ Summation of the score of three muscles in both shoulders resulted in a score of 25 out of $30 .{ }^{48}$ Elbow flexion ranged from a grade 2 to $5 .^{45-47,49,52}$ Wrist extension ranged from 3.3 to $4 .^{45,52}$ Elbow extension ranged from 0 to $2 .^{46,47}$ The mean wrist flexion was $1.5 .^{45}$ The mean motor score of the five key muscles of both upper extremities was 19 or 20 out of $50 .^{48,50,51}$

\section{Respiratory function}

Most selected studies assessed subjects with a tetraplegia. Time since injury usually exceeded 10 years. In paraplegia, mean FEV1 ranged from 86 to $98 \%$ of the predicted value for an age-, gender- and height-matched able-bodied population (weighted mean 90\%; Figure 3). The mean FVC ranged from 81 to $86 \%$ of the predicted value (weighted mean $85 \%$ ). In tetraplegia, mean FEV1 ranged from 40 to $80 \%$ of the predicted value (weighted mean $59 \%$ ). The mean FVC ranged from 37 to $61 \%$ of the predicted value (weighted mean 55\%).

\section{Discussion}

Level of $\mathrm{VO}_{2 \text { peak }}$ and $P \mathrm{O}_{\text {peak }}$

Relatively low values for $V \mathrm{O}_{2 \text { peak }}$ and $\mathrm{PO}_{\text {peak }}$ were a common finding and can be attributed to the dependency on arm exercise, the extent of paralysis, the reduced sympathetic control and the relative inactivity, which compromise physical capacity in SCI. ${ }^{18,31,36,67}$ ACE in sedentary able-bodied persons is suggested to induce an oxygen uptake of $70 \%$ of the oxygen uptake that can be reached during a treadmill running test. ${ }^{68}$ Assuming that the $70 \%$ ratio applies to persons with a paraplegia, the mean of $1.511 / \mathrm{min}$ corresponds to $2.161 / \mathrm{min}$. This is comparatively low, especially because daily use of a wheelchair may induce a training effect in persons with a paraplegia, and therefore, they may even be compared to an able-bodied population practiced in arm-exercise. $^{18,20,69}$ It indicates that factors like paralysis of lower limbs, altered autonomic control and inactivity do compromise physical capacity in paraplegia.

In paraplegia, the weighted mean $V \mathrm{O}_{2 \text { peak }}$ in $\mathrm{WCE}$ was higher than during ACE. This is in agreement with another study, which suggested that during WCE a larger muscle mass is activated, because muscles involved in stabilization of the trunk, and in the (un)coupling of the hand to the rim will be used. ${ }^{24,70}$ However, this is inconsistent with studies that assessed the same population alternately with both methods (Figure 4). These studies showed no significant differences in $V \mathrm{O}_{2 \text { peak }},{ }^{21,24,71,72}$ or an even higher $V \mathrm{O}_{2 \text { peak }}$ during ACE than during WCE. ${ }^{20,71}$ The inconsistency could be attributed to the fact that the present review compared results from different populations. The subjects studied during ACE were generally less active, and tested sooner after injury than subjects studied during WCE. Persons with long-standing SCI generally have a higher $V \mathrm{O}_{2 \text { peak }}$ than persons with a recent SCI. ${ }^{12,73}$ Protocol differences could also explain the differences found; ${ }^{20,23,43,74}$ overall, the ACE started at a higher power output, and had greater subsequent increments. It is suggested that greater increments may underestimate peak values. $^{43}$

The weighted mean $\mathrm{PO}_{\text {peak }}$ was lower in WCE than during ACE. This is consistent with other studies that assessed the same population alternately with both methods (Figure 4), ${ }^{20,24,71,72}$ and suggests that the discontinuous and more complex movement pattern of 
Table 1 '(a) Paraplegia: maximal exercise test using wheelchair ergometer or a wheelchair on a treadmill; (b) Paraplegia: maximal exercise test using arm-cranking or handcycling; (c) Tetraplegia: maximal exercise test using wheelchair ergometer or a wheelchair on a treadmill; (d) Tetraplegia: maximal exercise test using arm-cranking or handcycling

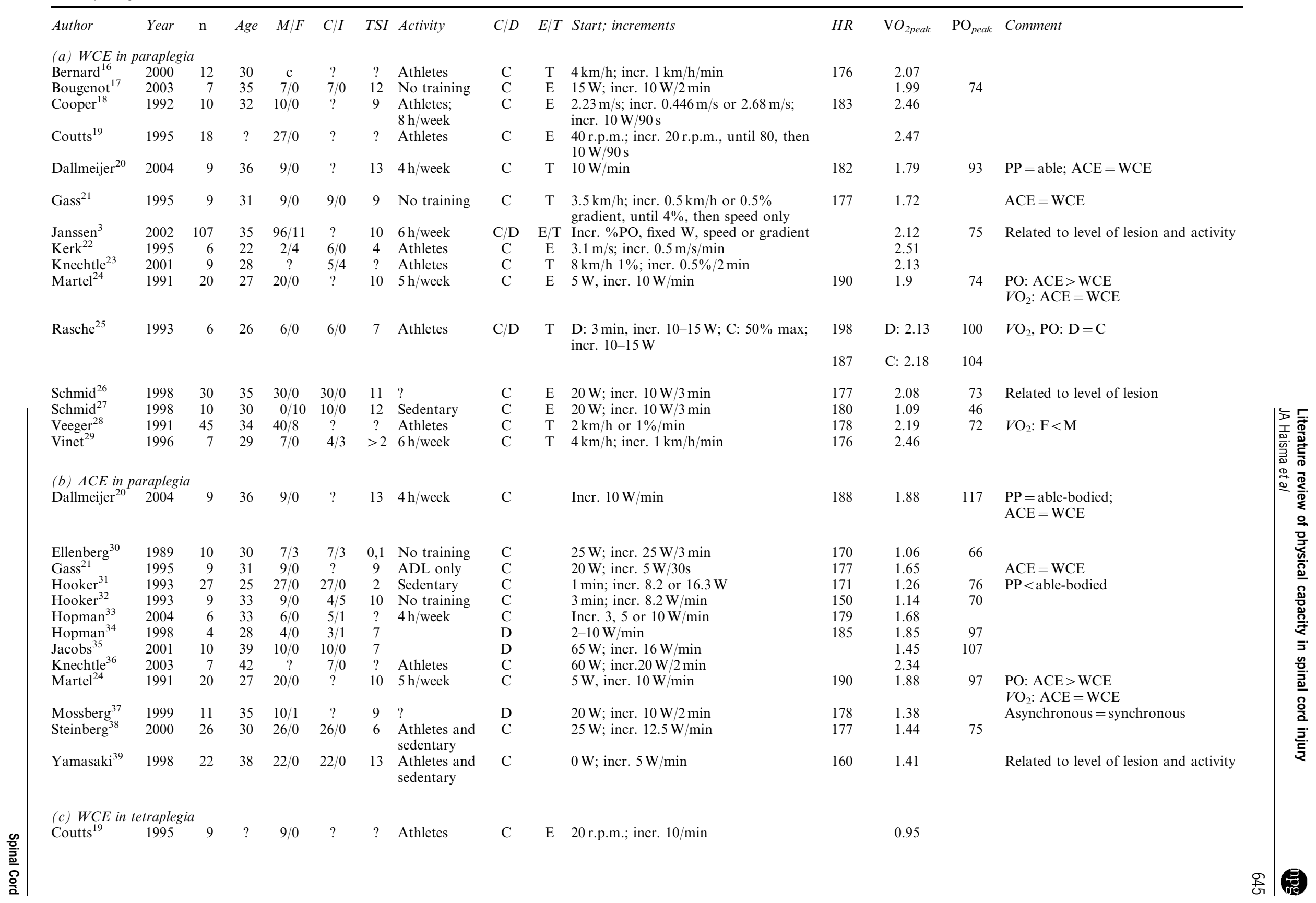


wheelchair propulsion (as opposed to the continuous movement in arm-cranking) may limit its efficiency and lead to a lower $\mathrm{PO}_{\text {peak }}$. The combination of the relatively high $V \mathrm{O}_{2 \text { peak }}$ with the low $\mathrm{PO}_{\text {peak }}$ supports the finding that wheelchair propulsion is mechanically less efficient than arm-cranking. ${ }^{24}$

Measuring $\mathrm{VO}_{2 \text { peak }}$ and $\mathrm{PO}_{\text {peak }}$

$V \mathrm{O}_{2 \text { peak }}$ and $\mathrm{PO}_{\text {peak }}$ have proven valid and sensitive outcome measures for the assessment of physical capacity, ${ }^{1}$ and should be included in the follow-up of persons with an SCI. The outcome of the maximal exercise tests were expressed as peak levels of oxygen uptake and power output (instead of maximal levels), because some subjects may have been able to activate a larger muscle mass, either through activation of the lower limbs (eg in those with incomplete lesion), or without the restraints from overuse and fatigue of the upper extremities. ${ }^{21,34,75}$ The large variability in results found in paraplegia may be attributed to differences in measurement protocol ${ }^{20,23,74}$ and study population. ${ }^{3}$ Because of lack of homogeneity, no consistent conclusions on the influence of a particular protocol can be drawn.

\section{Muscle strength of the upper extremity}

The HHD score for shoulder strength in subjects with a paraplegia compared favourably to an age- and gendermatched able-bodied population. ${ }^{76}$ This seems plausible, as in paraplegia muscle strength may be enhanced by daily use of the upper extremity. ${ }^{18}$ However, in tetraplegia, muscle strength additionally depends on the level and completeness of injury, neurological recovery and spasticity. In subjects with high cervical lesions, shoulder strength was reduced to $50 \%$ of values found in subjects with a paraplegia, or in the ablebodied population. ${ }^{44,76}$ The strength of elbow flexion and wrist extension was reduced to $15-30 \%$ of that in the able-bodied population. ${ }^{47,52,76}$ However, elbow extension showed relatively greater strength (30-50\% of that in the able-bodied population). ${ }^{47,76}$ The range of reported strength within the same muscle group may be attributed to subjects with incomplete lesions, who have a haphazard innervation pattern. Additionally, daily wheelchair use may have had a training effect in some subjects, and may cause overuse in others.

\section{Measuring muscle strength of the upper extremity}

Most studies incorporated the widely recognized and practical MMT and this was the motivation for choosing the MMT score as an outcome measure. However, the different scales and summations used hamper comparison between studies. The MMT score has other limitations, when compared to the HHD. Firstly, it is an ordinal scale, and therefore summations are not very meaningful. Secondly, it is a subjective score, probably sensitive to observer-bias. ${ }^{77}$ Thirdly, it is limited in the ability to identify change for grades 4 and 
Table 2 (a) Muscle strength of the upper extremity in subjects with a paraplegia; (b) muscle strength of the upper extremity in subjects with a tetraplegia

\begin{tabular}{|c|c|c|c|c|c|c|c|c|c|}
\hline Author & Year & $\mathrm{n}$ & Age & $M / F$ & $C / I$ & $T S I$ & $M / H$ & Strength upper extremity & Comment \\
\hline $\begin{array}{l}\text { (a) } \\
\text { May }^{44}\end{array}$ & 1997 & 11 & 28 & $10 / 1$ & $8 / 3$ & 8 & $\mathrm{H}$ & $\begin{array}{l}\text { Internal rotation shoulder } 30.6 \mathrm{~kg} \text {; } \\
\text { external rotation } 22.0 \mathrm{~kg}\end{array}$ & \\
\hline $\begin{array}{l}\text { (b) } \\
\text { Beninato }^{45}\end{array}$ & 2004 & 20 & 37 & $16 / 4$ & $13 / 7$ & $?$ & M & $\begin{array}{l}\text { Shoulder flex grade } 3.7 / \text { ext } 3.6 \text {; elbow } \\
\text { flex } 4.4 / \text { ext } 2.1 \text {; wrist flex } 1.5 / \text { ext } 3.3\end{array}$ & MMT 20-point scale \\
\hline Bryden $^{46}$ & 2004 & 43 & 32 & $36 / 7$ & $43 / 0$ & 6 & M & $\begin{array}{l}\text { Elbow ext: } 60 / 74 \text { grade } 0 ; 14 / 74 \text { grade } \\
1-2 ; \text { elbow flex: median } 4+; \text { range } 3-5\end{array}$ & MMT 20-point scale \\
\hline Burns ${ }^{47}$ & 2005 & 19 & 54 & $19 / 0$ & $9 / 10$ & $?$ & $\mathrm{M} / \mathrm{H}$ & $\begin{array}{l}\text { Elbow flex } 2 / 7 \text { grade } 3 ; 5 / 7 \text { grade } 4 ; \\
\text { ext } 6 / 12 \text { grade } 3 ; 6 / 12 \text { grade } 4 \\
\text { Make-test flex } 7.3 \mathrm{~kg} \text {; ext } 8.0 \mathrm{~kg} \\
\text { Break-test flex } 9.0 \mathrm{~kg} \text {; ext } 11.1 \mathrm{~kg}\end{array}$ & $\begin{array}{l}\text { Break test }>\text { make } \\
\text { test }\end{array}$ \\
\hline Fujiwara $^{48}$ & 1999 & 14 & 31 & $12 / 2$ & $14 / 0$ & 1.3 & M & $\begin{array}{l}\text { ASIA motor score: } 20 / 50 \\
\text { Shoulder score: } 25 / 30\end{array}$ & \\
\hline Herbison $^{49}$ & 1996 & 88 & 34 & $78 / 10$ & $?$ & $?$ & $\mathrm{M} / \mathrm{H}$ & $\begin{array}{l}\text { Elbow flexors: } 26 / 176 \text { grade } 3.5 \\
(\leftrightarrow 4 \mathrm{~kg}) ; 47 / 176 \text { grade } 4.0(\leftrightarrow 4.1 \mathrm{~kg}) \\
50 / 176 \text { grade } 4.5(\leftrightarrow 6.7 \mathrm{~kg}) ; 53 / 176 \\
\text { grade } 5(\leftrightarrow 9.0 \mathrm{~kg})\end{array}$ & $\begin{array}{l}\text { MMT 10-point scale. } \\
\text { HHD more sensitive } \\
\text { to change }\end{array}$ \\
\hline Hjeltnes $^{50}$ & 1998 & 10 & 25 & $10 / 0$ & $10 / 0$ & 0.3 & M & ASIA motor score: $19 / 50$ & $\begin{array}{l}\text { MMT 5-point scale. } \\
\text { Related to training }\end{array}$ \\
\hline Marino $^{51}$ & 1995 & 50 & $?$ & $47 / 3$ & $50 / 0$ & 1 & M & ASIA: mean $19 / 50$; median $16 / 50$ & MMT 5-point scale \\
\hline $\mathrm{May}^{44}$ & 1997 & 12 & 27 & $10 / 2$ & $10 / 2$ & 5 & $\mathrm{H}$ & $\begin{array}{l}\text { Internal rotation shoulder } 14.8 \mathrm{~kg} \\
\text { External rotation } 11.7 \mathrm{~kg}\end{array}$ & \\
\hline Schwartz $^{52}$ & 1992 & 122 & $?$ & $122 / 0$ & $?$ & 0.2 & $\mathrm{M} / \mathrm{H}$ & $\begin{array}{l}\text { MMT grade elbow flex } 5 \text {; wrist extensor } \\
\text { grade } 4 \text {. } \\
\text { HHD: elbow flex left } 8.0 \mathrm{~kg} \text {, right } 9.2 \mathrm{~kg} \text {; } \\
\text { wrist ext left } 6.3 \text {, right } 6.6 \mathrm{~kg}\end{array}$ & $\begin{array}{l}\text { MMT 10-point scale; } \\
\text { HHD more sensitive } \\
\text { to change }\end{array}$ \\
\hline
\end{tabular}

Muscle strength of the upper extremity in paraplegia (a) and tetraplegia (b). M/F: ratio male/female; TSI: time since injury (years); $\mathrm{C} / \mathrm{I}$ : complete/incomplete; $\mathrm{M} / \mathrm{H}$ : manual muscle testing or hand-held dynamometry; $\leftrightarrow$ : corresponds to; ASIA = summation of MMT grade elbow flexion, wrist extension, elbow extension, finger flexion, finger spread; Shoulder score: sum scapula abductors, shoulder adductors and extensors

5 , and the registration of recovery is restricted by a ceiling effect. ${ }^{49,52,77-79}$ Fourthly, it seems less valid, because it has a limited correlation with isokinetic dynamometry, which is often regarded the gold standard for the assessment of muscle strength, but is not manageable in use. ${ }^{44,77,80}$ The HHD score has shown to be valid, and has a good reliability in SCI, both with experienced and inexperienced examiners. $44,47,49$

Muscle strength is an important component of physical capacity, and is related to functioning. ${ }^{81}$ Because outcome measures need to be valid, sensitive to change and reliable, consensus needs to be reached on how to assess strength. HHD seems a valuable tool for the evaluation of muscle strength in SCI.

\section{Level of respiratory function}

In subjects with a tetraplegia, the respiratory function was greatly reduced as compared to an age-, gender- and height-matched able-bodied population, whereas in paraplegia the scores were relatively normal. This is consistent with other reports, which suggest that the level of lesion is inversely correlated with respiratory function. ${ }^{10,82}$ When the thoracic and lumbar segments are injured, muscles of expiration are affected, while injury to the upper cervical cord additionally affects muscles of inspiration. ${ }^{10,82}$ Furthermore, increased inactivity in tetraplegia may add to the reduced respiratory function. ${ }^{4}$ Both FEV1 and FVC were reduced, hence the ratio FEV1/FVC remained stable, which suggests that the respiratory problems are mostly restrictive in nature. ${ }^{53}$ However, it is suggested that with loss of the sympathetic influence from the upper six thoracic segments, the parasympathetic bronchoconstriction remains unopposed. ${ }^{55,58,59}$ This, together with airway obstruction following possible mucus collection, may result in additional obstructive problems. ${ }^{64}$

The variability found in outcome in tetraplegia may be attributed to population differences. Studies that included subjects with incomplete lesions, ${ }^{53,54,83}$ or those who were able to perform a maximal exercise test, ${ }^{41}$ were expected to have higher scores. Smoking was related to a reduced respiratory function in subjects with a paraplegia; surprisingly, however, these studies reported no significant relation between smoking and respiratory function in tetraplegia. ${ }^{53,54,83}$ Therefore, on the basis of these studies, smoking cannot be held responsible for population-related differences in outcome in tetraplegia. 
Table 3 (a) Respiratory function in subjects with a paraplegia; (b) respiratory function in subjects with a tetraplegia

\begin{tabular}{|c|c|c|c|c|c|c|c|c|c|c|c|c|}
\hline Author & Year & $\mathrm{n}$ & Age & $M / F$ & $C / I$ & Smoking & $T S I$ & FEV1 & FEV $1 \%$ & $F V C$ & $F V C \%$ & Comment \\
\hline \multicolumn{13}{|l|}{ (a) } \\
\hline Alemenoff ${ }^{53}$ & 1995 & 81 & 54 & $?$ & $27 / 54$ & $53 \mathrm{~N} ; 28 \mathrm{C}$ & 23 & 3.18 & 90 & 4.20 & 86 & $\begin{array}{l}\text { Related to level of lesion } \\
\text { and smoking }\end{array}$ \\
\hline Bernard $^{16}$ & 2000 & 12 & 30 & $?$ & $?$ & $?$ & $?$ & 4.09 & 98 & & & \\
\hline Kerk $^{22}$ & 1995 & 6 & 22 & $2 / 4$ & $6 / 0$ & $?$ & 4 & & & 3.0 & & \\
\hline $\operatorname{Linn}^{54}$ & 2000 & 41 & 40 & $19 / 22$ & $41 / 0$ & $\dot{\mathrm{N}}$ & 14 & & 89 & & 85 & Related to smoking \\
\hline Schilero $^{55}$ & 2005 & 15 & 49 & $15 / 0$ & $?$ & $\begin{array}{l}6 \mathrm{~N} ; 7 \mathrm{~F} \\
2 \mathrm{C}\end{array}$ & 16 & 3.17 & 86 & 4.18 & 84 & $\begin{array}{l}\mathrm{TP}<\mathrm{PP} ; \text { related to } \\
\text { bronchodilatator use }\end{array}$ \\
\hline Schilero $^{56}$ & 2004 & 5 & 40 & $?$ & $2 / 3$ & $\begin{array}{l}1 \mathrm{~N} ; 3 \mathrm{~F} \\
1 \mathrm{C}\end{array}$ & 19 & 3.50 & & 4.26 & & \\
\hline Silva $^{57}$ & 1998 & 12 & 31 & $12 / 0$ & $12 / 0$ & $\mathrm{~N}$ & $?$ & 3.62 & 84 & 4.05 & 81 & $\begin{array}{l}\mathrm{PP}<\text { able; related to } \\
\mathrm{ACE} \text { training }\end{array}$ \\
\hline \multicolumn{13}{|l|}{ (b) } \\
\hline Almenoff ${ }^{53}$ & 1995 & 84 & 46 & $?$ & $12 / 72$ & $55 \mathrm{~N} ; 29 \mathrm{C}$ & 16 & 2.40 & 64 & 2.94 & 59 & \multirow[t]{2}{*}{$\begin{array}{l}\text { Related to level, } \\
\text { completeness of lesion }\end{array}$} \\
\hline Almenoff $^{58}$ & 1995 & 25 & 43 & $25 / 0$ & $6 / 19$ & $10 \mathrm{C} ; 15 \mathrm{~N}$ & 11 & 2.07 & 55 & 2.46 & 50 & \\
\hline Gass $^{41}$ & 1980 & 9 & 34 & $?$ & $8 / 1$ & $3 \mathrm{C}$ & 12 & 2.57 & 80 & 2.38 & & \\
\hline Grimm $^{59}$ & 2000 & 32 & 42 & $?$ & $12 / 20$ & $\begin{array}{l}14 \mathrm{~N} ; 11 \mathrm{~F} ; \\
7 \mathrm{C}\end{array}$ & 14 & 2.47 & 62 & 3.07 & 58 & \\
\hline Liaw $^{60}$ & 2000 & 20 & 34 & $16 / 4$ & $20 / 0$ & $2 \mathrm{C}$ & 0.2 & 1.20 & 40 & 1.4 & 37 & Related to training \\
\hline $\operatorname{Linn}^{54}$ & 2000 & 35 & 40 & $16 / 19$ & $35 / 0$ & $\mathrm{~N}$ & 14 & & 57 & & 52 & \\
\hline Lougheed $^{61}$ & 2001 & 6 & 32 & $5 / 1$ & $6 / 0$ & $\begin{array}{l}2 \mathrm{~N} ; 2 \mathrm{~F} \\
2 \mathrm{C}\end{array}$ & 7 & 2.27 & 57 & 2.67 & 53 & \\
\hline Rutchik $^{62}$ & 1998 & 10 & 36 & $10 / 0$ & $4 / 6$ & $\begin{array}{l}4 \mathrm{~N} ; 5 \mathrm{~F} \\
1 \mathrm{C}\end{array}$ & 9 & 2.25 & 54 & 2.81 & 51 & Related to training \\
\hline Schilero $^{55}$ & 2005 & 15 & 42 & $15 / 0$ & $?$ & $\begin{array}{l}6 \mathrm{~N} ; 7 \mathrm{~F} ; \\
2 \mathrm{C}\end{array}$ & 13 & 2.29 & 56 & 2.91 & 55 & $\mathrm{TP}<\mathrm{PP} ; \mathrm{TP}<$ able \\
\hline Schilero $^{56}$ & 2004 & 5 & 45 & $?$ & $2 / 3$ & $3 \mathrm{~F} ; 2 \mathrm{C}$ & 17 & 2.28 & & 2.97 & & $\begin{array}{l}\text { Related to } \\
\text { bronchodilatator use }\end{array}$ \\
\hline Spungen $^{63}$ & 1999 & 10 & 41 & $10 / 0$ & $4 / 6$ & $9 \mathrm{~N} ; 1 \mathrm{C}$ & 16 & 2.23 & 56 & 2.79 & 53 & Related to steroid use \\
\hline Spungen ${ }^{64}$ & 1993 & 34 & 45 & $34 / 0$ & $34 / 0$ & $\begin{array}{l}12 \mathrm{~N} ; 14 \mathrm{~F} ; \\
8 \mathrm{C}\end{array}$ & 12 & 2.97 & & 2.12 & & \\
\hline Walker ${ }^{65}$ & 1989 & 15 & 28 & $11 / 4$ & $0 / 15$ & $\mathrm{~N}$ & $>2$ & & & 2.60 & 61 & Related to training \\
\hline Wang $^{66}$ & 2002 & 15 & 41 & $?$ & $15 / 0$ & $?$ & 4 & 1.83 & 61 & 2.16 & 59 & Related to training \\
\hline
\end{tabular}

Respiratory function in subjects with a paraplegia (a) and subjects with a tetraplegia (b). M/F: ratio male/female; TSI: time since injury (years); C/I: complete/incomplete; smoking history: N: never; F: former; C: current; FEV1: forced expiratory flow in 1 s (1); FEV1\%: forced expiratory flow as percentage of predicted; FVC: forced vital capacity (1); FVC\% forced vital capacity as percentage of predicted; TP: tetraplegia; PP: paraplegia

\section{Measuring respiratory function}

The respiratory function was expressed as a percentage of predicted values from an age-, gender- and heightmatched able-bodied suitable reference population. However, because level of lesion is an important determinant of respiratory function, one would ideally want to correct for this, but it would require a large comparative database to make a valid correction.

All selected studies used the American Thoracic Society (ATS) criteria for accepting individual spirometry results. This may lead to biased results, because the most impaired subjects are not able to meet these criteria. It has been suggested that when the criteria are modified, reproducibility can be guaranteed without loss of results from these subjects. ${ }^{84}$

Respiratory complications are responsible for about $25 \%$ of deaths following an SCI ${ }^{85}$ and $68 \%$ of persons with an SCI experience respiratory complaints. ${ }^{86}$
Improved respiratory function may contribute to the prevention of complications; therefore, evaluation of this function is important in SCI rehabilitation.

\section{Limitations}

We aimed at integrating evidence on different aspects of physical capacity. However, the cardiovascular function was not investigated for two reasons. Firstly, stroke volume is not easily measured in rehabilitation practice. Secondly, peak heart rate is not a valid measure of physical capacity in SCI, and is not sensitive to change during training. ${ }^{1,34,75}$ Reasons for this may be that upper body exercise is limited by local fatigue and overuse (rather than cardiovascular strain), and that peak heart rate varies too much in persons with a tetraplegia. ${ }^{20,21,24,71}$

Overall, a positive selection is shown which will bias the results. Firstly, most studies focused on male 

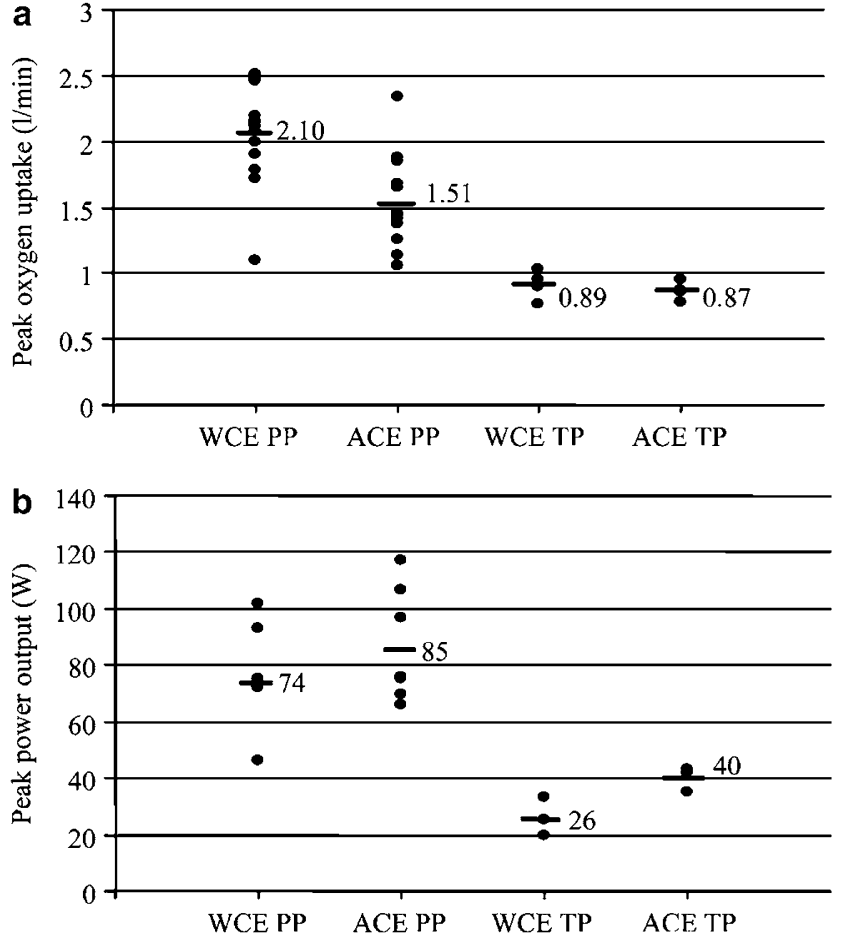

Figure 2 (a) Mean peak oxygen uptake (1/min) for the included studies; PP: paraplegia; TP: tetraplegia; WCE: wheelchair exercise test; ACE: arm-cranking or hand-cycling. Weighted mean peak oxygen uptake for included studies is specified. (b) Mean peak power output (W) for the included studies; PP: paraplegia; TP: tetraplegia; WCE: wheelchair exercise test; ACE: arm-cranking or hand-cycling. Weighted mean peak power output for included studies is specified

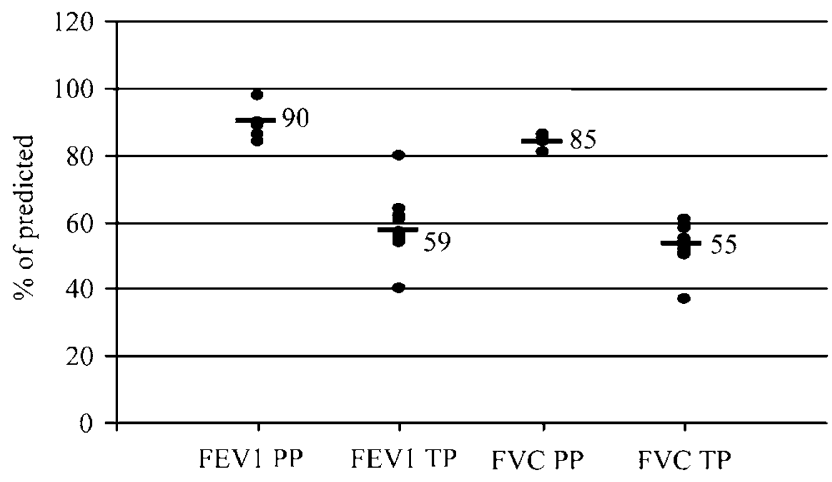

Figure 3 Mean respiratory function (as percentage of predicted values for an age-, gender- and height-matched able-bodied population) for included studies; PP: paraplegia; TP: tetraplegia; FEV1: forced expiratory flow in $1 \mathrm{~s}$; FVC: forced vital capacity. Weighted mean FEV1 or FVC for included studies is specified

athletes. ${ }^{3,50,57}$ Secondly, only those able to perform the tests were included, possibly excluding subjects with high cervical lesions. Thirdly, only those willing to participate were included. Hence, motivation and state

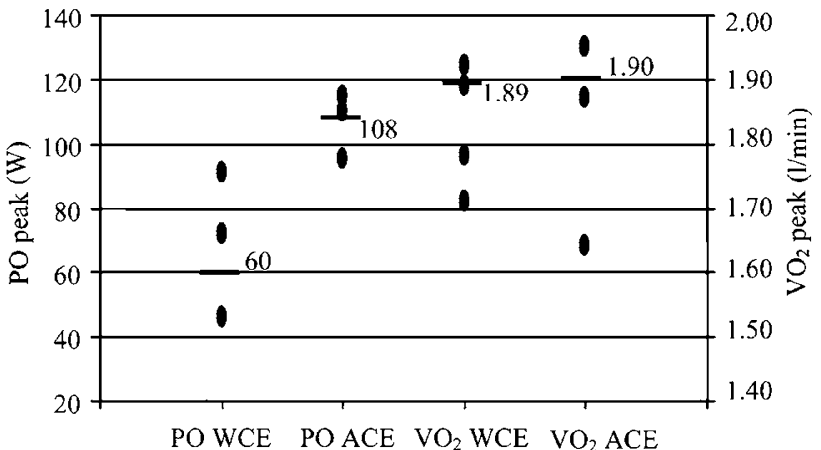

Figure 4 Mean peak power output $\left(\mathrm{PO}_{\text {peak }}\right)$ and peak oxygen uptake $\left(V \mathrm{O}_{2 \text { peak }}\right)$ for four study populations; WCE: wheelchair exercise test; ACE: arm-cranking or hand-cycling. Weighted mean peak power output or peak oxygen uptake for four studies is specified

of mood could influence both the selected population and performance during the tests. Owing to lack of homogeneity among the included studies, the integration of findings did not provide consistent and comparative values.

\section{Conclusions}

The level of physical capacity is reduced and varies in persons with an SCI. The variation between results is caused by population and methodological differences. To allow interpretation and comparison of results, researchers should meticulously describe the population and the methods used. Standardized assessment of physical capacity in clinical practice and rehabilitation research is needed for the effective prediction and evaluation of progress in future. The present study provides suggestions for the parameters to be determined and methods to be used. Additionally, it provides a descriptive database for physical capacity in persons with an SCI and, with caution, these data may be used as reference material in rehabilitation and training.

\section{References}

1 Stewart MW, Melton-Rogers SL, Morrison S, Figoni SF. The measurement properties of fitness measures and health status for persons with spinal cord injuries. Arch Phys Med Rehabil 2000; 81: 394-400.

2 Muraki S, Tsunawake N, Tahara Y, Hiramatsu S, Yamasaki M. Multivariate analysis of factors influencing physical work capacity in wheelchair-dependent paraplegics with spinal cord injury. Eur J Appl Physiol 2000; 81: 28-32.

3 Janssen TW, Dallmeijer AJ, Veeger DJ, van der Woude LH. Normative values and determinants of physical capacity in individuals with spinal cord injury. $J$ Rehabil Res Dev 2002; 39: 29-39.

4 Dallmeijer AJ, van der Woude LH, Hollander PA, Angenot EL. Physical performance in persons with spinal 
cord injuries after discharge from rehabilitation. Med Sci Sports Exerc 1999; 31: 1111-1117.

5 Dallmeijer AJ, van der Woude LH. Health related functional status in men with spinal cord injury: relationship with lesion level and endurance capacity. Spinal Cord 2001; 39: 577-583.

6 Noreau L, Shephard RJ, Simard C, Pare G, Pomerleau P. Relationship of impairment and functional ability to habitual activity and fitness following spinal cord injury. Int J Rehabil Res 1993; 16: 265-275.

7 Noreau L, Shephard RJ. Return to work after spinal cord injury: the potential contribution of physical fitness. Paraplegia 1992; 30: 563-572.

8 Hjeltnes N, Jansen T. Physical endurance capacity, functional status and medical complications in spinal cord injured subjects with long-standing lesions. Paraplegia 1990; 28: 428-432.

9 Yekutiel M, Brooks ME, Ohry A, Yarom J, Carel R. The prevalence of hypertension, ischaemic heart disease and diabetes in traumatic spinal cord injured patients and amputees. Paraplegia 1989; 27: 58-62.

10 Noreau L, Shephard RJ. Spinal cord injury, exercise and quality of life. Sports Med 1995; 20: 226-250.

11 Manns PJ, Chad KE. Determining the relation between quality of life, handicap, fitness, and physical activity for persons with spinal cord injury. Arch Phys Med Rehabil 1999; 80: 1566-1571.

12 Dallmeijer AJ, van der Woude LH, Hollander AP, van As HH. Physical performance during rehabilitation in persons with spinal cord injuries. Med Sci Sports Exerc 1999; 31: 1330-1335.

13 Dallmeijer AJ et al. Hand-rim wheelchair propulsion capacity during rehabilitation of persons with spinal cord injury. J Rehabil Res Dev 2005; 42: 55-64.

14 Verhagen AP et al. The delphi list: a criteria list for quality assessment of randomized clinical trials for conducting systematic reviews developed by Delphi consensus. J Clin Epidemiol 1998; 51: 1235-1241.

15 Gardner MJ, Machin D, Campbell MJ. Use of check lists in assessing the statistical content of medical studies. Br Med J (Clin Res Ed) 1986; 292: 810-812.

16 Bernard PL, Mercier J, Varray A, Prefaut C. Influence of lesion level on the cardioventilatory adaptations in paraplegic wheelchair athletes during muscular exercise. Spinal Cord 2000; 38: 16-25.

17 Bougenot MP et al. Effects of a wheelchair ergometer training programme on spinal cord-injured persons. Spinal Cord 2003; 41: 451-456.

18 Cooper RA, Horvath SM, Bedi JF, Drechsler-Parks DM, Williams RE. Maximal exercise response of paraplegic wheelchair road racers. Paraplegia 1992; 30: 573-581.

19 Coutts KD, McKenzie DC. Ventilatory thresholds during wheelchair exercise in individuals with spinal cord injuries. Paraplegia 1995; 33: 419-422.

20 Dallmeijer AJ, Zentgraaff ID, Zijp NI, van der Woude LH. Submaximal physical strain and peak performance in handcycling versus handrim wheelchair propulsion. Spinal Cord 2004; 42: 91-98.

21 Gass EM, Harvey LA, Gass GC. Maximal physiological responses during arm cranking and treadmill wheelchair propulsion in t4-t6 paraplegic men. Paraplegia 1995; 33: 267-270.

22 Kerk JK et al. Effect of an abdominal binder during wheelchair exercise. Med Sci Sports Exerc 1995; 27: 913-919.
23 Knechtle B, Kopfli W. Treadmill exercise testing with increasing inclination as exercise protocol for wheelchair athletes. Spinal Cord 2001; 39: 633-636.

24 Martel G, Noreau L, Jobin J. Physiological responses to maximal exercise on arm cranking and wheelchair ergometer with paraplegics. Paraplegia 1991; 29: 447-456.

25 Rasche W, Janssen TW, Van Oers CA, Hollander AP, Van der Woude LH. Responses of subjects with spinal cord injuries to maximal wheelchair exercise: comparison of discontinuous and continuous protocols. Eur J Appl Physiol Occup Physiol 1993; 66: 328-331.

26 Schmid A et al. Catecholamines, heart rate, and oxygen uptake during exercise in persons with spinal cord injury. J Appl Physiol 1998; 85: 635-641.

27 Schmid A et al. Physical performance and cardiovascular and metabolic adaptation of elite female wheelchair basketball players in wheelchair ergometry and in competition. Am J Phys Med Rehabil 1998; 77: 527-533.

28 Veeger HE, Hadj Yahmed M, van der Woude LH, Charpentier P. Peak oxygen uptake and maximal power output of Olympic wheelchair-dependent athletes. Med Sci Sports Exerc 1991; 23: 1201-1209.

29 Vinet A, Bernard PL, Poulain M, Varray A, Le Gallais D, Micallef JP. Validation of an incremental field test for the direct assessment of peak oxygen uptake in wheelchairdependent athletes. Spinal Cord 1996; 34: 288-293.

30 Ellenberg M, MacRitchie M, Franklin B, Johnson S, Wrisley D. Aerobic capacity in early paraplegia: implications for rehabilitation. Paraplegia 1989; 27: 261-268.

31 Hooker SP, Greenwood JD, Hatae DT, Husson RP, Matthiesen TL, Waters AR. Oxygen uptake and heart rate relationship in persons with spinal cord injury. Med Sci Sports Exerc 1993; 25: 1115-1119.

32 Hooker SP, Greenwood JD, Boyd LA, Hodges MR, McCune LD, McKenna GE. Influence of posture on arm exercise tolerance and physiologic responses in persons with spinal cord injured paraplegia. Eur J Appl Physiol 1993; 67: 563-566.

33 Hopman MT, Houtman S, Groothuis JT, Folgering HT. The effect of varied fractional inspired oxygen on arm exercise performance in spinal cord injury and able-bodied persons. Arch Phys Med Rehabil 2004; 85: 319-323.

34 Hopman MT, Dueck C, Monroe M, Philips WT, Skinner JS. Limits to maximal performance in individuals with spinal cord injury. Int J Sports Med 1998; 19: 98-103.

35 Jacobs PL, Nash MS, Rusinowski JW. Circuit training provides cardiorespiratory and strength benefits in persons with paraplegia. Med Sci Sports Exerc 2001; 33: 711-717.

36 Knechtle B, Muller G, Willmann F, Eser P, Knecht H. Comparison of fat oxidation in arm cranking in spinal cord-injured people versus ergometry in cyclists. Eur J Appl Physiol 2003; 90: 614-619.

37 Mossberg K, Willman C, Topor MA, Crook H, Patak S. Comparison of asynchronous versus synchronous arm crank ergometry. Spinal Cord 1999; 37: 569-574.

38 Steinberg LL et al. Catecholamine response to exercise in individuals with different levels of paraplegia. Braz J Med Biol Res 2000; 33: 913-918.

39 Yamasaki $\mathrm{M}$ et al. Relationship between physical characteristics and physiological responses during maximal arm cranking in paraplegics. Spinal Cord 1998; 36: 579-583.

40 Dallmeijer AJ, Hopman MT, Angenot EL, van der Woude LH. Effect of training on physical capacity and physical strain in persons with tetraplegia. Scand J Rehabil Med 1997; 29: 181-186. 
41 Gass GC, Watson J, Camp EM, Court HJ, McPherson LM, Redhead P. The effects of physical training on high level spinal lesion patients. Scand J Rehabil Med 1980; 12: 61-65.

42 Hopman MT, Dallmeijer AJ, Snoek G, van der Woude LH. The effect of training on cardiovascular responses to arm exercise in individuals with tetraplegia. Eur $J \mathrm{Appl}$ Physiol Occup Physiol 1996; 74: 172-179.

43 Lasko-McCarthey P, Davis JA. Protocol dependency of $V \mathrm{O}_{2}$ max during arm cycle ergometry in males with quadriplegia. Med Sci Sports Exerc 1991; 23: 1097-1101.

44 May LA, Burnham RS, Steadward RD. Assessment of isokinetic and hand-held dynamometer measures of shoulder rotator strength among individuals with spinal cord injury. Arch Phys Med Rehabil 1997; 78: 251-255.

45 Beninato M, O'Kane KS, Sullivan PE. Relationship between motor FIM and muscle strength in lower cervical-level spinal cord injuries. Spinal Cord 2004; 42: 533-540.

46 Bryden AM, Kilgore KL, Lind BB, Yu DT. Triceps denervation as a predictor of elbow flexion contractures in c5 and c6 tetraplegia. Arch Phys Med Rehabil 2004; 85: $1880-1885$.

47 Burns SP, Breuninger A, Kaplan C, Marin H. Hand-held dynamometry in persons with tetraplegia: comparison of make-versus-break testing techniques. Am J Phys Med Rehabil 2005; 84: 22-29.

48 Fujiwara T, Hara Y, Akaboshi K, Chino N. Relationship between shoulder muscle strength and functional independence measure (FIM) score among C6 tetraplegics. Spinal Cord 1999; 37: 58-61.

49 Herbison GJ, Isaac Z, Cohen ME, Ditunno Jr JF. Strength post-spinal cord injury: myometer $v s$ manual muscle test. Spinal Cord 1996; 34: 543-548.

50 Hjeltnes $\mathrm{N}$, Wallberg-Henriksson H. Improved work capacity but unchanged peak oxygen uptake during primary rehabilitation in tetraplegic patients. Spinal Cord 1998; 36: 691-698.

51 Marino RJ, Rider-Foster D, Maissel G, Ditunno JF. Superiority of motor level over single neurological level in categorizing tetraplegia. Paraplegia 1995; 33: 510-513.

52 Schwartz S, Cohen ME, Herbison GJ, Shah A. Relationship between two measures of upper extremity strength: manual muscle test compared to hand-held myometry. Arch Phys Med Rehabil 1992; 73: 1063-1068.

53 Almenoff PL, Spungen AM, Lesser M, Bauman WA. Pulmonary function survey in spinal cord injury: influences of smoking and level and completeness of injury. Lung 1995; 173: 297-306.

54 Linn WS, Adkins RH, Gong Jr H, Waters RL. Pulmonary function in chronic spinal cord injury: a cross-sectional survey of 222 southern California adult outpatients. Arch Phys Med Rehabil 2000; 81: 757-763.

55 Schilero GJ, Grimm DR, Bauman WA, Lenner R, Lesser M. Assessment of airway caliber and bronchodilator responsiveness in subjects with spinal cord injury. Chest 2005; 127: 149-155.

56 Schilero GJ, Grimm D, Spungen AM, Lenner R, Lesser M. Bronchodilator responses to metaproterenol sulfate among subjects with spinal cord injury. J Rehabil Res Dev 2004; 41: $59-64$.

57 Silva AC et al. Effect of aerobic training on ventilatory muscle endurance of spinal cord injured men. Spinal Cord 1998; 36: 240-245.
58 Almenoff PL, Alexander LR, Spungen AM, Lesser MD, Bauman WA. Bronchodilatory effects of ipratropium bromide in patients with tetraplegia. Paraplegia 1995; 33: 274-277.

59 Grimm DR, Chandy D, Almenoff PL, Schilero G, Lesser M. Airway hyperreactivity in subjects with tetraplegia is associated with reduced baseline airway caliber. Chest 2000; 118: 1397-1404.

60 Liaw MY, Lin MC, Cheng PT, Wong MK, Tang FT. Resistive inspiratory muscle training: its effectiveness in patients with acute complete cervical cord injury. Arch Phys Med Rehabil 2000; 81: 752-756.

61 Lougheed MD, Flannery J, Webb KA, O'Donnell DE. Respiratory sensation and ventilatory mechanics during induced bronchoconstriction in spontaneously breathing low cervical quadriplegia. Am J Resp Crit Care Med 2002; 166: $370-376$.

62 Rutchik A, Weissman AR, Almenoff PL, Spungen AM, Bauman WA, Grimm DR. Resistive inspiratory muscle training in subjects with chronic cervical spinal cord injury. Arch Phys Med Rehabil 1998; 79: 293-297.

63 Spungen AM, Grimm DR, Strakhan M, Pizzolato PM, Bauman WA. Treatment with an anabolic agent is associated with improvement in respiratory function in persons with tetraplegia: a pilot study. Mt Sinai J Med 1999; 66: 201-205.

64 Spungen AM, Dicpinigaitis PV, Almenoff PL, Bauman WA. Pulmonary obstruction in individuals with cervical spinal cord lesions unmasked by bronchodilator administration. Paraplegia 1993; 31: 404-407.

65 Walker J, Cooney M, Norton S. Improved pulmonary function in chronic quadriplegics after pulmonary therapy and arm ergometry. Paraplegia 1989; 27: 278-283.

66 Wang TG, Wang YH, Tang FT, Lin KH, Lien IN. Resistive inspiratory muscle training in sleep-disordered breathing of traumatic tetraplegia. Arch Phys Med Rehabil 2002; 83: 491-496.

67 Figoni SF. Perspectives on cardiovascular fitness and SCI. J Am Paraplegia Soc 1990; 13: 63-71.

68 Bergh U, Kanstrup IL, Ekblom B. Maximal oxygen uptake during exercise with various combinations of arm and leg work. J Appl Physiol 1976; 41: 191-196.

69 O’Toole ML, Hiller DB, Crosby LO, Douglas PS. The ultraendurance triathlete: a physiological profile. Med Sci Sports Exerc 1987; 19: 45-50.

70 Gass GC, Camp EM. The maximum physiological responses during incremental wheelchair and arm cranking exercise in male paraplegics. Med Sci Sports Exerc 1984; 16: $355-359$.

71 Wicks JR, Oldridge NB, Cameron BJ, Jones NL. Arm cranking and wheelchair ergometry in elite spinal cordinjured athletes. Med Sci Sports Exerc 1983; 15: 224-231.

72 Simard C, Noreau L, Pare G, Pomerleau P. Maximal physiological response during exertion in quadriplegic subjects. Can J Appl Physiol 1993; 18: 163-174.

73 Hjeltnes N. Cardiorespiratory capacity in tetra- and paraplegia shortly after injury. Scand $J$ Rehabil Med 1986; 18: 65-70.

74 Hartung GH, Lally DA, Blancq RJ. Comparison of treadmill exercise testing protocols for wheelchair users. Eur J Appl Physiol Occup Physiol 1993; 66: 362-365.

75 van der Woude LH, Bouten C, Veeger HE, Gwinn T. Aerobic work capacity in elite wheelchair athletes: a crosssectional analysis. Am J Phys Med Rehabil 2002; 81: 261-271. 
76 Phillips BA, Lo SK, Mastaglia FL. Muscle force measured using 'break' testing with a hand-held myometer in normal subjects aged 20-69 years. Arch Phys Med Rehabil 2000; 81: $653-661$

77 Noreau L, Vachon J. Comparison of three methods to assess muscular strength in individuals with spinal cord injury. Spinal Cord 1998; 36: 716-723.

78 Ditunno Jr JF, Stover SL, Freed MM, Ahn JH. Motor recovery of the upper extremities in traumatic quadriplegia: a multicenter study. Arch Phys Med Rehabil 1992; 73: 431-436.

79 Burns AS, Ditunno JF. Establishing prognosis and maximizing functional outcomes after spinal cord injury: a review of current and future directions in rehabilitation management. Spine 2001; 26: S137-S145.

80 van Tuijl JH, Janssen-Potten YJ, Seele HA. Evaluation of upper extremity motor function tests in tetraplegics. Spinal Cord 2002; 40: 51-64.

81 Marino RJ, Huang M, Knight P, Herbison GJ, Ditunno Jr JF, Segal M. Assessing selfcare status in quadriplegia: comparison of the quadriplegia index of function (QIF) and the functional independence measure (FIM). Paraplegia 1993; 31: 225-233.

82 Winslow C, Rozovsky J. Effect of spinal cord injury on the respiratory system. Am J Phys Med Rehabil 2003; 82: 803-814.

83 Linn WS, Spungen AM, Gong Jr H, Adkins RH, Bauman WA, Waters RL. Forced vital capacity in two large outpatient populations with chronic spinal cord injury. Spinal Cord 2001; 39: 263-268.

84 Kelley A, Garshick E, Gross ER, Lieberman SL, Tun CG, Brown R. Spirometry testing standards in spinal cord injury. Chest 2003; 123: 725-730.

85 DeVivo MJ, Krause JS, Lammertse DP. Recent trends in mortality and causes of death among persons with spinal cord injury. Arch Phys Med Rehabil 1999; 80: 1411-1419.

86 Spungen AM, Grimm DR, Lesser M, Bauman WA, Almenoff PL. Self-reported prevalence of pulmonary symptoms in subjects with spinal cord injury. Spinal Cord 1997; 35: 652-657. 